\title{
Editorial
}

\section{Mechanistic Understanding of Antioxidants Impact on Cognitive Function in Geriatric Canines}

\author{
Lauren R.Thomas, DVM'*; Hayley A. Booth, BSc ${ }^{1 *}$; Kaleigh E. Beane, BSc ${ }^{2 *}$; Kristopher A. Bottoms, BSc ${ }^{1 *}$; Sami Dridi, PhD ${ }^{3 *}$ \\ *Equal participation \\ 'Department of Animal Science, University of Arkansas, Fayetteville, AR 7270I, USA \\ ${ }^{2}$ Department of Human Environmental Science, University of Arkansas, Fayetteville, AR 7270I, USA \\ ${ }^{3}$ Department of Poultry Science, Division of Agriculture, University of Arkansas, Fayetteville, AR 7270 I, USA \\ "Corresponding author \\ Sami Dridi, PhD \\ Center of Excellence for Poultry Science, University of Arkansas, I260 W, Maple Street, Fayetteville AR 7270I, USA; Tel. (479)-575-2583; Fax: (479)-575-7I39; \\ E-mail: dridi@uark.edu
}

Article information

Received: October $7^{\text {th }}$ 2018; Accepted: October $11^{\text {th }}, 2018$; Published: October $17^{\text {th }}, 2018$

Cite this article

Thomas LR, Booth HA, Beane KE, Bottoms KA, Dridi S. Mechanistic understanding of antioxidants impacts on cognitive function in geriatric canines. Adv Food Technol Nutr Sci Open J. 2018; 4(2): e6-e8. doi: 10.17|40/AFTNSOJ-4-e0I4

\section{INTRODUCTION}

$\mathrm{C}$ anine cognitive dysfunction syndrome (CDS) is a collection of symptoms, or behavioral changes, described specifically in dogs of advanced age unrelated to any other diagnosable illness. Symptoms may include an altered sleep-wake cycle, newly developed destructive behavior, inappropriate elimination, excessive vocalization, pacing or wandering, and altered social interaction with the owner. ${ }^{1-4}$ In regards to aging, the brain is one of the most susceptible tissues in the body because of its high oxygen requirement, poor endogenous antioxidant capacity, and limited regenerative ability. ${ }^{5,6} \mathrm{~A}$ number of pathologic changes have been identified in the aged canine brain, many of which have also been described in humans diagnosed with Alzheimer's disease (AD). As a result, the dog is often used as a high-relevant comparative animal model for studies on AD in humans. ${ }^{7-9}$ The most commonly recognized changes in the canine brain include decreased total brain volume (or atrophy), enlargement of the lateral ventricles, choroid plexus, meningeal and vascular fibrosis, neuronal loss, decreased neuronal regenerative capacity, lipofuscin buildup, intracytoplasmic inclusion formation, and diffuse $\beta$-amyloid plaque formation-specifically in the frontal cortex and hippocampal regions. ${ }^{5,7,10,11}$ Several studies have suggested a significant correlation between $\beta$-amyloid deposition and the severity of cognitive dysfunction in aged canines ${ }^{4}$, similar to that which occurs in humans with Alzheimer's disease though the exact mechanisms between these changes and the development of cognitive dysfunction syndrome in canines is yet to be fully established. ${ }^{5}$ However, it has been shown that oxidative damage to lipids and proteins due to reactive oxygen species increases in the brain with age. $^{12}$ As a result, diets fortified with antioxidants may help to prevent and/or mitigate some of these destructive changes, thus decreasing the incidence and/or severity of cognitive dysfunction syndrome. ${ }^{1,4}$

\section{Free Radicals, Reactive Oxygen Species and Antioxidants}

Generally speaking, any molecule that contains at least one unpaired electron in the outer shell is intensely reactive and is called a "free radical" or, if it contains oxygen, a reactive oxygen species (ROS). ${ }^{13}$ The body spontaneously creates reactive oxygen species such as the superoxide, hydroxyl, peroxyl ( $\mathrm{RO} 2 \bullet)$, alkoxyl $(\mathrm{RO} \bullet)$, and hydroperoxyl (HO2 •) free radicals as by-products of cellular respiration. In low concentrations, ROS aid in maturing cellular structures, immune system destruction of foreign pathogens, and cellular signaling. ${ }^{14-16}$ When excess ROS remain un-neutralized by the body's natural defenses, they can cause oxidative stress on the surrounding tissues. This is because the free radicals undergo further reactions with surrounding molecules leading to the formation of peroxides, subsequent degradation into smaller molecular units, and then formation of dimer aggregates. This then detrimentally affects the functional efficiency and the productive ability of these cells. The free radical theory of aging was developed in the mid- $20^{\text {th }}$ century and suggests that aging is caused by the continued detrimental effects of free radicals over an organism's lifespan as well as a decrease in the ability to recover from cellular damage caused by free radicals and other reactive oxygen species (ROS). ${ }^{17}$

Antioxidants are substances found in the diet that have the ability to reduce the effect of ROS and potentially delay the effects of aging associated with cognitive dysfunction. In order to combat ROS within cells, the body protects itself by using various antioxidant mechanisms. Antioxidants and their mechanisms are classified as either enzymatic (superoxide dismutase (SOD), catalase (CAT), and glutathione peroxidase (GSHPx)) or non-enzymatic (vitamin E, vitamin C, plant polyphenols, carotenoids, and glutathione). ${ }^{18,19}$ For the purposes of this editorial, we chose to focus primarily on the functions of the naturally occurring, non-enzy- 
matic antioxidants, vitamin $\mathrm{E}$ and vitamin $\mathrm{C}$, which are commonly incorporated into commercial canine diets specifically formulated to combat brain aging. ${ }^{20,21}$

Vitamin E ( $\alpha$-tocopherol) works by impeding free radical chain reactions. It intercepts lipid peroxyl radicals (LOO•), and terminates lipid peroxidation chain reactions. ${ }^{18}$ The resulting radical $(\alpha$-tocopherol-O• $)$ is considered stable under normal conditions, and helps prevent lipid peroxidation.

\section{$\mathrm{LOO}^{*}+\alpha$-tocopherol-OH à LOOH + -tocopherol-O}

Vitamin C (ascorbic acid 2) is a free radical scavenger. It generates vitamin $\mathrm{E}$ within cell membranes by combining with glutathione $(\mathrm{GSH})$ or other compounds capable of donating reducing equivalents. Once vitamin $\mathrm{C}$ donates an electron to lipid radicals, the structure is converted to an ascorbate radical ${ }^{18,19,22}$ which then prevents the lipid peroxidation chain reaction (Fig. 1). ${ }^{18}$

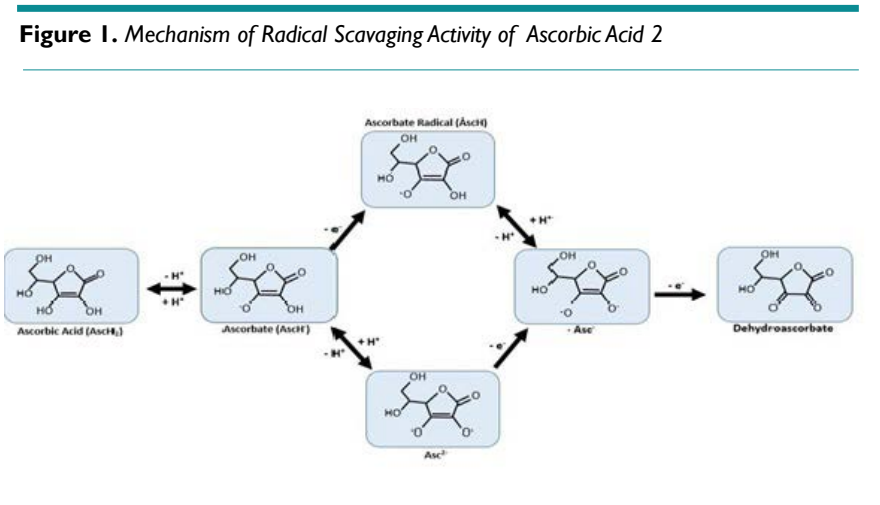

\section{Antioxidants and Canine Cognitive Function}

Aged dogs have been used in studies to determine the effects of antioxidant supplementation on the reduction of oxidative stress in the brain and the consequent effects on cognitive function. Several recent studies have used aged beagles to determine if a combination of behavioral enrichment and antioxidant supplementation would begin to more closely resemble cognitive function of younger beagles given the same treatment., ${ }^{43-26}$ The antioxidantrich diet contained a broad spectrum of antioxidants (vitamins $\mathrm{E}$ and $\mathrm{C}$ as well as those occurring in fruits and vegetables such as spinach, tomato, grape and carrot) as well as two mitochondrial cofactors (carnitine and lipoic acid). ${ }^{25}$ Over a nearly three year period, the aged dogs showed significant improvement in areas such as spatial attention and oddity discrimination. ${ }^{4,27}$ Other areas such as visual discrimination and frontal function of the brain maintained performance in antioxidant enriched diets. However, in aged dogs with untreated diets there was a significant decline. ${ }^{25}$ Dogs subjected to both antioxidant-enriched diets as well as behavioral enrichment showed superior improvements compared to either treatment alone. ${ }^{24,25}$ It should be noted that the young dogs with antioxidant enriched diets did not show significant difference in cognitive function from the young dog control group. ${ }^{28}$
This finding suggests that aged dogs in particular benefit from antioxidant supplementation. Dogs progression in cognitive deficits as they age is similar to that of humans, thus making them a useful model in age-related cognitive dysfunction research. The beneficial effect of an antioxidant-rich diet on aged dogs prove a possible therapeutic approach that may be translated to humans with cognitive dysfunction, such as Alzheimer's Disease. ${ }^{30}$

\section{Current Dietary Recommendations}

As described above, studies have shown that a mixed diet of antioxidants is needed to reach maximum results. ${ }^{29,30}$ Vitamin E, vitamin $C, \beta$-carotene, and trace minerals including selenium, copper, zinc, and manganese, are common antioxidant sources utilized in canine diets. ${ }^{30}$ Additionally, antioxidants synergistically work with mitochondrial cofactors, such as alpha-lipoic acid and Acetyl-Lcarnitine, to reduce the effect of ROS and oxidative stress on age-related cognitive dysfunction ${ }^{4,30,31}$ and should be incorporated into the diet as well. Two mainstream diets enriched with antioxidants and labeled to help reduce signs of cognitive dysfunction syndrome in dogs include the Hill's Prescription Diet Canine b/d and the Purina Pro Plan Bright Mind. Both diets are enhanced with a mixture of vitamins $\mathrm{E}$ and $\mathrm{C}$ as well as carnitine and lipoic acid or selenium and vitamin $\mathrm{A}$ respectively. ${ }^{20,21}$ Currently, there are no formally published daily dosage recommendations for any of the individual antioxidants in relation to canine CDS.

\section{CONFLICTS OF INTEREST |}

The authors declare that they have no conflicts of interest.

\section{REFERENCES |}

1. Roudebush P, Zicker SC, Cotman CW, et al. Nutritional management of brain aging in dogs. J Am Vet Med Assoc. 2005; 227(5): 722-728. doi: 10.2460/javma.2005.227.722

2. Neilson JC, Hart BL, Cliff KD, Ruehl WW. Prevalence of behavioral changes associated with age-related cognitive impairment in dogs. J Am Vet Med Assoc.. 2001; 218: 1787-1791. doi: 10.2460/ javma.2001.218.1787

3. Bain MJ, Hart BL, Cliff KD, et al. Predicting behavioral changes associated with age-related cognitive impairment in dogs. $J$ Am Vet Med Assoc. 2001; 218(11): 1792-1795. doi: 10.2460/javma.2001.218.1792

4. Cotman CW, Head E, Muggenburg BA, et al. Brain aging in the canine: A diet enriched in antioxidants reduces cognitive dysfunction. Neurobiol Aging. 2002; 23(5): 809-818. doi: 10.1016/S01974580(02)00073-8

5. Youssef SA, Capucchio MT, Rofina JE, et al. Pathology of the aging brain in domestic and laboratory animals, and animal models of human neurodegenerative disease. Vet Pathol. 2016; 53(2): 327-348. doi: 10.1177/0300985815623997 6. Dror Y, Stern F, Gomori MJ. Vitamins in the prevention or delay 
7(1): 65-74. doi: 10.2174/157015909787602823

of cognitive disability of aging. Curr Aging Sci. 2014; 7(3): 187-213. doi: 10.2174/1874609808666150201214955

7. Takeuchi Y, Uetsuka K, Murayama M, et al. Complementary distributions of amyloid- $\beta$ and neprilysin in the brains of dogs and cats. Vet Pathol. 2008; 45(4): 455-466. doi: 10.1354/vp.45-4-455

8. Czasch S, Paul S, Baumgartner W. A comparison of immunohistochemical and silver staining methods for the detection of diffuse plaques in the aged canine brain. Neurobiol Aging. 2006; 27(2): 293 305. doi: 10.1016/j.neurobiolaging.2005.02.017

9. Dickson DW. Neuropathological diagnosis of Alzheimer's disease: A perspective from longitudinal clinic-pathologic studies. Neurobiol Aging. 1997; 18(4): S21-26. doi: 10.1101/cshperspect. a006189

10. Tapp DP, Siwak CT, Gao FQ, et al. Frontal lobe volume, function and $\beta$-amyloid pathology in a canine model of aging. J Neurosci. 2004; 24(38): 8205-8213. doi: 10.1523/JNEUROSCI.1339-04.2004

11. Borras D, Ferrer I, Pumarola M. Age-related changes in the brain of dog. Vet Pathol. 1999; 36(3): 202-211. doi: 10.1354/vp.363-202

12. Head E, Liu J, Hagen T, et al. Oxidative damage increases with age in a canine model of human brain aging. J Neurochem. 2002; 82(2): 375-381. doi: 10.1046/j.1471-4159.2002.00969.x

13. Aiken C, Kaake R, Wang X, Huang L. Oxidative stress-mediated regulation of proteasome complexes. Mol Cell Proteomics. 2011; 10(5): doi: 10.1074/mcp.M110.006924

14. DeCoursey T, Ligeti E. Regulation and termination of NADPH oxidase activity. Cell Mol Life Sci. 2005; 62(19-20): 2173-2193. doi: $10.1007 / \mathrm{s} 00018-005-5177-1$

15. Schreck R, Baeuerle P. A role for oxygen radicals as second messengers. Trends Cell Biol. 1991; 1(2-3): 39-42. doi: 10.1016/09628924(91)90072-H

16. Ignarro L, Cirino G, Casini A, Napoli C. Nitric oxide as a signaling molecule in the vascular system: An Overview. J Cardiovasc Pharmacol. 1999; 34(6): 879-886.

17. Harman D. Aging: A theory based on free radical and radiation chemistry. J Gerontol. 1956; 11(3): 298-300. doi: 10.1093/ geronj/11.3.298

18. Nimse SB, Pal D. Free Radicals, natural antioxidants, and their reaction mechanisms. RSC Advances. 2015; 5: 27986-28006. doi: $10.1039 / \mathrm{c} 4 \mathrm{ra13315c}$

19. Uttara B, Singh AV, Zamboni P, Mahajan RT. Oxidative stress and neurodegenerative diseases: A review of upstream and downstream antioxidant therapeutic options. Curr Neuropharmacol. 2009;
20. Prescription Diet Canine b/d, Hill's Pet Nutrition Inc, Topeka, Kansas.

21. Purina Pro Plan Bright Mind Adult 7+, Nestle Purina Petcare Co, St. Louis, Missouri.

22. Padayatty SJ, Katz A, Wang Y, et al. Vitamin C as an antioxidant: Evaluation of its role in disease prevention. J Am Coll Nutr. 2003; 22(1): 18-35. doi: 10.1080/07315724.2003.10719272

23. Milgram N, Zicker S, Head E, et al. Dietary enrichment counteracts age-associated cognitive dysfunction in canines. Neurobiol Aging. 2002; 23(5): 737-745. doi: 10.1016/S0197-4580(02)00020-9

24. Milgram N, Head E, Zicker S, et al. Long-term treatment with antioxidants and a program of behavioral enrichment reduces agedependent impairment in discrimination and reversal learning in beagle dogs. Exp Gerontol. 2004; 39(5): 753-765. doi: 10.1016/j. exger.2004.01.007

25. Milgram NW, Head E, Zicker SC, et al. Learning ability in aged beagle dogs is preserved by behavioral enrichment and dietary fortification: A two-year longitudinal study. Neurobiol Aging. 2005; 26(1): 77-90. doi: 10.1016/j.neurobiolaging.2004.02.014

26. Nippak PM, Mendelson J, Muggenburg B, Milgram NW. Enhanced spatial ability in aged dogs following dietary and behavioral enrichment. Neurobiol Learn Mem. 2007; 87(4): 610-623. doi: 10.1016/j.nlm.2007.01.001

27. Milgram NW, Head E, Muggenburg B, et al. Landmark discrimination learning in the dog: Effects of age, an antioxidant fortified food, and cognitive strategy. Neurosci Biobehav Rev. 2002; 26(6): 679695. doi: 10.1016/S0149-7634(02)00039-8

28. Siwak CT, Tapp PD, Head E, et al. Chronic antioxidant and mitochondrial cofactor administration improves discrimination learning in aged but not young dogs. Prog Neuropsychopharmacol Biol Psychiatry. 2005; 29(3): 461- 469. doi: 10.1016/j.pnpbp.2004.12.011

29. Head E, Zicker SC. Nutraceuticals, aging, and cognitive dysfunction. Vet Clin North Am Small Anim Pract. 2004; 34(1): 217-228. doi: 10.1016/j.cvsm.2003.09.007

30. Opii WO, Joshi G, Head E, et al. Proteomic identification of brain proteins in the canine model of human aging following a long-term treatment with antioxidants and a program of behavioral enrichment: Relevance to alzheimers disease. Neurobiol Aging. 2008; 29(1): 51-70. doi: 10.1016/j.neurobiolaging.2006.09.012

31. Snigdha S, Rivera CD, Milgram NW, Cotman CW. Effect of mitochondrial cofactors and antioxidants supplementation on cognition in the aged canine. Neurobiol Aging. 2016; 37: 171-178. doi: 10.1016/j.neurobiolaging.2015.09.015 